\title{
Mapeando as Relações Sociais em Aglomerados de Empresas
}

\author{
Mapping Social relationship in Industrial Districts
}

Edgar Reyes Junior ${ }^{1}$ - Universidade Federal de Roraima - UFRR Cláudio dos Reis Gonçalo ${ }^{2}$ - Universidade do Vale de Itajaí- UNIVALI Cristiane Nascimento Brandão ${ }^{3}$ - Fundação Getúlio Vargas/FGV-EAESP

\begin{abstract}
Resumo
Este artigo analisa as relações sociais internas e externas de empresas localizadas no distrito industrial de couro de Estância Velha - Brasil. Estas relações foram analisadas sob a perspectiva da confiança, a qual considera como elementos constituintes: as características das pessoas, a continuidade dos processos e aspectos institucionais. Foram estudadas todas as 53 empresas do setor de curtumes do distrito que formaram uma rede social com 250 empresas de 6 diferentes países, abrangendo toda a cadeia coureiro-calçadista. Neste estudo foi utilizada a metodologia de análise de redes sociais que permitiu a mensuração de diferentes de relacionamentos. Os resultados indicam que os principais determinantes da confiança foram as relações processuais e institucionais; que as relações não comerciais têm maior impacto que as relações comerciais; que a reputação é o principal componente da confiança baseada em instituições e que esta é mais dependente das relações de amizade, que das relações comerciais. Também pode ser identificado que o índice relacional construído para a análise aumenta em função do aumento do porte da empresa; do tempo de existência da organização; do aumento da escolaridade do empresário; e da atividade exportadora.
\end{abstract}

Palavras chave: Aglomerações industriais - análise de redes sociais - confiança capital social

\begin{abstract}
This work analyzes internal and external social relations in companies located in the industrial district of leather from Estância Velha - Brazil. These relationships were analyzed from the perspective of trust, which considered as constitutive elements: the people's characteristics, continuity of processes and institutional aspects. We studied all 53 companies from the tanneries of the district formed a social network with 250 companies from six different countries, covering the entire leatherfootwear chain. In this study we used the methodology of social network analysis that allowed measurement of different relationship. The results indicate that the main determinants from trust relations suffered procedures and institutional, the trade relations that are not commercial have greater impact than the commercial relations; the reputation is the main component of trust which is based in institutions, and it is more dependent on friendship than commercial relation it. It can also be identified as the relational index made with the analysis increase the size of company, the time of life about the organization, increasing the knowledge of businessperson, and export activity.
\end{abstract}

Keyword: Industrial districts - Social network analysis - Trust - Social capital

\footnotetext{
${ }^{1}$ Doutor em Administração, e-mail: edgarreyes2000@yahoo.com.br

${ }^{2}$ Doutor em Engenharia de Produção, email: cgoncalo@unisinos.br

${ }^{3}$ Mestranda em Administração, email: cristianne.brandao@gmail.com
} 


\section{Introdução}

Os estudos tradicionais de aglomerados de empresas têm sido investigados a partir das relações entre input-output de um setor produtivo e das influências das características dos arranjos. Estas categorias de investigação vêm sendo fundamentadas teoricamente na existência de externalidades oriundas da proximidade geográfica, as quais podem afetar as vantagens competitivas através da influência sobre a produtividade e o crescimento do próprio aglomerado (Marshall, 1984: Porter, 1999). Entretanto, a análise destas vantagens competitivas têm sido analisadas exclusivamente a partir da perspectiva econômica.

A atividade econômica em um dado ambiente geográfico tem lugar a partir de um processo social de divisão de trabalho, tendendo a identificar as vantagens coletivas do ambiente geográfico (Scott, 1998, Becattini 1999; 2002). Da mesma forma, ao se analisar o capital social de distritos industriais, diversos estudiosos consideram este capital como um bem coletivo (Putnam, 1996; Fukuyama,1996). Todavia o desempenho das empresas em aglomerados que o compõe é variado, de forma que algumas crescem e se desenvolvem, enquanto outras encerram suas atividades. Se todas as empresas geograficamente próximas estão sujeitas às mesmas condições externas, tais como variação cambial ou políticas públicas, algo existe que as diferencia individualmente.

A causa dessa diferenciação dos atores pode estar relacionada com os relacionamentos estabelecidos entre os atores baseados em confiança, que, por sua vez, pode ser considerada como um estado psicológico que compreende a intenção de aceitar certa vulnerabilidade baseada em expectativas positivas em relação aos outros (Rousseau et al.; 1998).

O distrito industrial pode ser visto como uma rede de empresas, que se encontram próximas geograficamente e que tem na confiança uma forma de governança informal (Uzzi, 1996). A análise de redes sociais pode ser utilizada como forma de mapeamento e individualização destas relações estabelecidas, tanto entre os elementos constituintes da rede pesquisada (Kwong; 2002; Wassermann e Faust 1997; Borgatti e Everett, 1997), como também àquela formada entre atores da rede e agentes externos (Oh, Labianca e Chung, 2006; Bonacich 1972). O outro tipo de capital social do grupo ocorre quando todas as relações que estão sendo estudadas pertencem aos indivíduos. 
Destas considerações surge a seguinte questão de pesquisa: De que forma as relações sociais dos executivos influencia no desempenho individual em aglomerações de empresas?

Após esta introdução, serão analisados teoricamente os aglomerados de empresas, a confiança interpessoal e as redes sociais. Posteriormente serão apresentados os aspectos metodológicos, a análise de dados e as considerações finais.

\section{Referencial teórico}

\subsection{Aglomerados De Empresas}

Existe uma grande variação de nomenclaturas e conceitos referentes ao tema aglomerações de empresas, tais como Clusters, Distritos industriais, Arranjos Produtivos Locais, Complexos industriais e Sistemas Produtivos Locais. Segundo Costa e Costa (2005), ao se identificar determinadas características da organização industrial de uma dada atividade que podem estar relacionadas com o seu sucesso competitivo, passa-se a utilizá-las como guia na identificação de atributos estruturais de outros setores produtivos.

Os Clusters de Marshall (1984) são empresas aglomeradas, capazes de se apropriar de economias externas geradas pela aglomeração dos produtores, independentemente dos atributos individuais das empresas, tais como porte das mesmas. Já Cocco et al (1999) entendem-no como o fenômeno das redes industriais de pequenas e médias empresas, assim como as ligações destas com o meio sócio-territorial onde estão circunscritas as aglomerações setoriais.

Para Becattini (1992), um distrito industrial é mais que um simples cluster, já que se caracteriza pela presença ativa de um grupo de pessoas ou empresas em uma determinada zona histórico-geográfica. No distrito, ao contrário de outros ambiente, a comunidade e as empresas tendem a fundir-se. Para o autor, é indispensável que cada empresa se especialize em uma ou poucas fases dos processos de produção típicos do distrito.

Os distritos industriais são sistemas produtivos definidos geograficamente, caracterizados por um grande número de empresas que se ocupam de diversas fases e formas na elaboração de um produto homogêneo. Eles seriam ainda caracterizados por um grande número de empresas que se ocupam de diversas fases e formas na elaboração de um produto homogêneo, uma grande proporção dessas empresas são micro e pequenas empresas (Pyke e Sengenberger,1992). 
Segundo Costa e Costa (2005), a denominação Arranjo Produtivo Local (APL) está associada aos estudos sobre clusters e distritos industriais. Contudo, clusters e distritos industriais são organizações produtivas cujas características apresentam caráter histórico, resultado do ambiente econômico, da cultura e das relações sociais locais. Para Cassiolato e Lastres (1999) são aglomerações territoriais de atores econômicos, políticos e sociais, focados em um conjunto específico de atividades econômicas, que apresentam vínculos mesmo que incipientes. O conceito apóia-se num entendimento mais apropriado sobre os conceitos chave da literatura neo-schumpeteriana de aprendizado e inovação e numa dimensão territorial que seja capaz de captar esses conceitos.

Neste trabalho, considera-se um aglomerado de empresas, como uma entidade sócio-territorial que se caracteriza pela presença ativa de uma comunidade de pessoas ou conjunto de empresas que tenha sido historicamente determinada, já que a história pressupõe a amarração social necessária à formação das relações. Observe-se que neste conceito não se faz referência a tamanho ou grau de formalização das relações.

Marshall (1984) foi o pioneiro em observar, a partir da análise dos distritos industriais na Inglaterra no final do século XIX, que a presença concentrada de empresas em uma mesma região pode prover ao conjunto dos produtores vantagens competitivas que não seriam verificadas se eles estivessem atuando isoladamente. As vantagens derivadas da concentração geográfica estão associadas não apenas ao aumento do volume de produção, mas também com os ganhos de organização e desenvolvimento decorrentes da maior integração entre os agentes. A concentração de produtores especializados estimula a promoção de formas de integração entre os agentes, o que faz com que os segredos da indústria deixem de ser secretos e "pairem no ar", de modo que todos sejam capazes de absorvê-los.

O autor aponta três tipos básicos de economias oriundas da especialização dos agentes produtivos localizados, a existência concentrada de mão-de-obra qualificada e com habilidades específicas ao setor ou segmento industrial em que as empresas locais são especializadas, a presença de fornecedores especializados de bens e serviços aos produtores locais, e a presença de economias externas locais são as possibilidades de transbordamento (spillovers) de conhecimento e de tecnologia. 
Becattini $(1992,1999,2002)$ retoma os trabalhos de Marshall (1984) e afirma que, para a ocorrência desse fenômeno, se faz necessária a inter-relação das pequenas empresas com as populações residentes neste território, de forma que os aspectos socioculturais dessas populações são de suma importância. Becattini (2002) traça paralelos entre o conceito marshalliano de "crédito social" com os conceitos de confiança e capital social ao identificar semelhanças entre os mesmos, quando Marshall inclui na análise instrumentos endosomáticos, como potencial intelectual e capacidade inovadora, que são inseparáveis de seu portador ou bens coletivos, local ou setorialmente, que não são intrinsecamente apropriáveis e que se consistem de uma rede sutil de relações interpessoais.

Tal idéia parece próxima de Grannovetter (1973) e sua noção de embeddedness, ao supor que a persecução de objetivos econômicos é sempre acompanhada de outros objetivos de natureza não econômica, tais como a sociabilidade, a aprovação, o status social ou o poder. Por outro lado, a ação econômica, como toda ação, está socialmente "impregnada" e não pode ser explicada através de movimentos individuais, já que depende de relações pessoais que os indivíduos mantêm entre si. Finalmente, as instituições econômicas, como qualquer instituição, não estão automaticamente determinadas por circunstancias externas, mas sim são socialmente construídas.

Da mesma maneira, a afirmação de Macias (2002), no sentido de que a organização em rede opera em uma lógica de intercambio que difere da lógica de mercado, já que as conexões sociais configuram as expectativas e oportunidades dos atores de forma distinta da lógica econômica e do comportamento do mercado. Deste modo, um maior ou menor nível de imbricamento pode conduzir a resultados não previstos pela explicação econômica.

Nos estudos sobre a Terza Itália, Becattini (1999) e Bagnasco (1999) apresentam as organizações em rede, ligadas pelo capital social, que seria formado por aspectos culturais e de confiança, sendo este o agente aglutinador das diferentes organizações existentes em uma dada região. Becattini (1999), aponta ainda para o fato de que, se faz necessária a inter-relação das pequenas empresas com as populações residentes neste território, de forma que os aspectos socioculturais dessas populações são de suma importância. A integração entre estas empresas e a população local que deve ter características sócio-culturais específicas, é indispensável. 
Para Amato Neto (2000) as redes interfirmas constituem-se no modo de regular a interdependência de sistemas complementares, como produção, pesquisa, coordenação, etc. sem agregá-los em uma única empresa. Trata-se de um tipo de agrupamento de empresas cujo objetivo principal é o de fortalecer as atividades dos participantes da rede, sem que haja necessariamente laços financeiros entre si. Trata-se, portanto de um modo de associação por afinidade e de natureza informal, que deixa cada uma das empresas responsável pelo seu próprio gerenciamento.

Partindo da nomenclatura da sociologia, Bagnasco (1999) identifica como fatores fundamentais para o desenvolvimento destas redes, a acumulação de capital inicial, capacidade de gestão e qualificação técnica, confiança recíproca e bom clima social, além de necessitarem, para obter maior competitividade, de flexibilidade em relação às demandas internas e externas (Verschoore, 2004).

O conceito de rede colaborativa assume uma importância relativa considerável na vida das organizações, uma vez que as redes de instituições, constituídas em torno de áreas de interesse comum, tem sido uma característica da postura cooperativa em busca de aumento de produtividade. A postura de cooperação é fortemente sustentada por processos de cooperação articulados em torno das redes colaborativas (RAUD, 1999) Segundo Balestrin e Vargas (2002), a colaboração surgiu à medida que a sociedade e as organizações foram se estruturando, levando pessoas e organizações a manterem inter-relações sociais.

Para Pyke e Sengenberger (1992), um sistema de cooperação entre empresas é composto geralmente por empresas de menor porte, tendo uma região por base e pertencendo a um mesmo setor econômico e incluindo as empresas a montante e a jusante, organizadas conjuntamente e que se valem das instituições locais, através de relacionamentos de competição e cooperação. Para Uzzi (1996), as características da rede em que as organizações estão inseridas determinam suas oportunidades potenciais e a posição na estrutura das redes e o tipo de relações mantidas pelas empresas com as demais define seu acesso a estes recursos.

Putnam (1996) salienta que as diversas partes componentes do agrupamento devem ter um mínimo de história comum, podendo ser manifestada através de questões étnicas, históricas, de valores, religiosas, preferências políticas, etc., além de uma cultura empresarial que valorize os laços cooperativos e uma tradição de apoio familiar a novos empresários. O autor salienta ainda que uma política de promoção, que cuide de aspectos relacionados à socialização e conscientização dos 
seus membros, incluindo noções de responsabilidade, compromisso, participação e consciência coletiva deve ser adotada.

\subsection{As Redes Sociais}

As redes sociais são definidas como um conjunto de dois elementos: atores (pessoas, instituições ou grupos) e suas conexões (Wasserman e Faust, 1994). Emirbayer e Goodwin (1994) destacam que as redes sociais são conjuntos de contatos que ligam vários atores, que podem ser de diferentes tipos, apresentarem conteúdos diferentes, bem como diferentes propriedades estruturais. Isto porque redes sociais referem-se a um conjunto de pessoas, ou organizações, ou ainda, outras entidades sociais conectadas por relacionamentos sociais, motivados pela amizade e por relações de trabalho ou compartilhamento de informações e, por meio dessas ligações, vão construindo e re-construindo a estrutura social (Emirbayer e Goodwin, 1994).

A análise de redes Sociais (ARS) é uma aproximação intelectual ampla para identificar as estruturas sociais que emergem das diversas formas de relações, mas também um conjunto específico de métodos e técnicas. As tradições dominantes nas Ciências Sociais construíram modelos explicativos a partir de modelos causais, que geralmente foram aplicados a estruturas macro, sociais ou econômicas. A partir de modelos intencionais que foram utilizados para construir explicações de natureza micro, que se centravam na conduta individual. O enfoque da Psicologia Social respondeu à necessidade de conectar ambos os níveis de análise e neste sentido, a ARS, se apresenta como una ferramenta útil (Borgatti e Everett, 1996).

Desta forma pode-se definir a ARS como um conjunto de técnicas de análise para o estudo formal das relações entre atores e para analisar as estruturas sociais que surgem em decorrência dessas relações ou da ocorrência de determinados eventos. A consolidação da análise de redes veio precisamente evidenciar os efeitos que os diferentes padrões e estruturas de rede têm em relação ao acesso dos membros a recursos (Granovetter, 1973). De maneira que o acesso a recursos, de qualquer tipo, parece estar fortemente associado à forma das redes sociais.

Para Hanneman (2001), a ARS de um sistema social é, antes de tudo, um conjunto estruturado de posições sociais. O conceito de papel aparece como uma variável dependente da posição. Em conseqüência, as dimensões valorativas e normativas da conduta são para a ARS, assim como as demais dimensões da motivação, mais efeito que causa. Ainda de acordo com Hanneman (2001), a análise de redes 
sociais é mais um ramo da sociologia matemática do que uma análise estatística ou quantitativa. A idéia básica de uma rede é simples: um conjunto de atores ou nós, pontos ou agentes entre os quais existem vínculos ou relações. Pode haver muitos ou poucos atores e pode existir uma ou mais classes de relações entre eles. De maneira geral, para se entender bem a rede, deve-se conhecer as relações entre cada par de atores da população estudada. O uso de técnicas matemáticas, como matrizes e gráficos, por exemplo, permite uma descrição mais adequada e concisa de suas características.

Britto (2002) relaciona as características estruturais das redes de empresas com sua capacidade para a divisão do trabalho e com o grau de saturação da estrutura da rede. O autor destaca um conjunto de medidas como significativas para a compreensão da estrutura de uma rede. Entre elas estão a densidade, o grau de centralidade, os pontos de passagem, que neste trabalho serão consideradas como grau de intermediação.

Na centralidade, as redes sociais enfatizam que o poder é baseado em relações. Um indivíduo não tem poder abstrato, somente se detém poder porque se pode influir sobre os demais. Devido ao fato de o poder ser, assim uma conseqüência dos padrões relacionais, a quantidade de poder nas diferentes estruturas sociais pode variar de forma que é uma propriedade sistêmica (macro) e relacional (micro) (Hanneman, 2001).

A maneira como um ator encontra-se inserido em uma rede relacional determina assim a medida das restrições e oportunidades que lhe é apresentada. Os atores que enfrentam menos restrições e tem mais oportunidades estão em posições estruturais mais favoráveis. Uma posição mais favorável significa ter melhores ofertas além de ser um foco da deferência e atenção daqueles em posição menos favorável (Emirbayer e Goodwin, 1994).

Um ator é localmente central se ele apresenta um grande número de conexões com outros pontos, e será globalmente central se possuir uma posição significantemente estratégica na rede como um todo (Scott, 2000). Rodrigues e Mérida (2006) identificam através dela os atores mais centrais, mais proeminentes, mais poderosos e com prestígio.

A abordagem relacional foca as conexões diretas e indiretas entre os atores (Emirbayer e Goodwin, 1994), para entender comportamentos e processos por meio da conectividade entre os atores. Para tanto, foram utilizadas as medidas de 
densidade, distância, grau de centralidade, centralidade de intermediação e centralidade geodésica e coesão social para cada uma das dimensões consideradas. Para Hannemam (2001), os subgrupos existentes em uma rede têm suas próprias normas, valores, orientações, sendo base para a solidariedade e o comportamento coletivo dentro do grupo. Wasserman e Faust (1994) afirmam que os subgrupos apresentam como propriedades gerais, a mutualidade e a freqüência dos laços, a proximidade e alcance entre membros dos subgrupos, e a freqüência relativa de laços entre membros fora e dentro dos subgrupos. Este conjunto de indicadores será analisado de forma pormenorizada na metodologia.

Estas relações sociais podem ser analisadas a partir da confiança estabelecida entre os atores da rede. A literatura organizacional sobre confiança apresenta inúmeros conceitos provenientes de diversas áreas do conhecimento, tais como a psicologia, a sociologia e a economia, o que conduziu a variadas definições do construto confiança (Singh e Sirdeshmukh, 2000). Apesar das divergências para a definição do construto confiança, Rousseau et al. (1998), propuseram uma definição consensual, em que a confiança é um estado psicológico que compreende a intenção de aceitar certa vulnerabilidade baseada em expectativas positivas das intenções ou dos comportamentos de outros.

A perspectiva de escolha racional apresenta uma orientação calculada em relação a risco através de escolhas racionais e eficientes, enquanto que na perspectiva de escolha relacional é inserida uma orientação social em relação a pessoas e a sociedade como um todo (Kramer, 2000). McAllister (1995) compreende a confiança no contexto dos relacionamentos, para o qual os laços emocionais que ligam indivíduos podem fornecer a base para a confiança, assim como sua importância nos relacionamentos de base afetiva e na qualidade do comportamento interpessoal (Mcallister, 1995).

Os achados de Uzzi (1996), indicam os atos de confiança como mecanismo de governança das relações enraizadas, que facilitaria a troca de recursos e informações, cruciais para a eficiência das organizações. Para o autor, a confiança é o único mecanismo de governança no qual se consegue voluntariamente trocas sem obrigações, tanto de produtos, como de serviços entre as empresas. Além disso, ela seria importante porque permitiria o acesso a recursos e a habilidade de adaptação frente a problemas não previstos. 
$\mathrm{Na}$ construção social da confiança, Zucker (1986) identifica a confiança como um mecanismo para coordenar as expectativas dos atores sociais. Para a autora, os atores sociais não são nem totalmente egoístas nem totalmente altruístas. Seu conceito de confiança está baseado na noção de um compartilhamento coletivo de significados e conhecimentos implícitos.

Neste trabalho consideram-se os tipos de confiança, oriundos das relações sociais estabelecidas em rede, segundo Zucker (1986), analisando a confiança baseada em características como formada pelas relações familiares. Para a confiança baseada em processos, consideram-se as dimensões comerciais e não comerciais, sendo a primeira formada pelas relações estabelecidas entre as empresas e seus clientes e fornecedores e a segunda formada, por um lado pelas relações de amizade entre empresários e por outro pelas empresas onde os empresários exerceram suas atividades conjuntamente, antes de assumirem sua atual função. A confiança baseada em instituições é analisada como formada pela reputação do respondente e pelas associações e agremiações a que pertence.

\section{Metodologia}

Neste estudo descritivo explicativo, o método de pesquisa empregado foi quantitativo, mais especificamente questionário com a inclusão da ARS, que possibilita avaliar tanto os aspectos descritivos dos relacionamentos, quanto às análises estatísticas causais de tais fenômenos (Hanneman, 2001), bem como os impactos dos mesmos sobre a atividade empresarial.

Escolheu-se incluir o método de análise de redes sociais por este incluir informações sobre o relacionamento entre os integrantes de um grupamento de empresas e pela pertinência do método na análise de fenômenos sociais. Os dados coletados para esta pesquisa foram essencialmente dados primários e de corte transversal.

Este estudo é censitário por demanda da própria ARS (Wasserman e Faust, 1994), assim foram investigadas todas as 53 empresas do setor couro, que estavam em operação no município de Estância Velha. Foram entrevistados os proprietários, diretores ou gerentes destas empresas, tendo sido consideradas as relações destes, como representativas das relações da organização, por serem os executivos das organizações aqueles que mantêm o maior número e as mais importantes relações externas da organização. 
Além das relações estabelecidas no interior do grupo analisado, foram consideradas as empresas do setor com outras localizações na identificação do impacto causado por estas relações sobre as dimensões analisadas. Os respondentes citaram outras 197 empresas e instituições, formando um universo total de 250 atores. Estas 197 empresas e instituições citadas pelo grupo pesquisado e localizadas em outros lugares são formadas por 31 acabadoras de couro, 32 curtumes completos, 66 fábricas de calçado, 22 fábricas e representações de produtos químicos, 15 associações e agremiações, 11 empresas prestadoras de serviços especializados, 8 empresas de exportação de couro e calçado, 7 empresas de comercialização de couros, 1 curtume de peles exóticas e uma escola técnica. Geograficamente estão localizadas principalmente nos Vales dos Sinos e do Paranhama, no Rio Grande do Sul, mas também nos Estados de São Paulo, Goiás, Ceará, Pernambuco, Bahia, Mato Grosso e em Arzignano na Itália e Leon no México.

A Coleta de dados foi desenvolvida pela aplicação de questionário com perguntas abertas e fechadas, formado por dois blocos de perguntas. O primeiro, formado por aspectos sócio demográficos, tanto relativas as características do respondente, como idade, gênero e escolaridade, foram questionados aspectos referentes à suas empresas, como porte, atividade exportadora e tempo de existência. Um segundo bloco foi formado por perguntas referentes aos aspectos relacionais dos atores, baseados no modelo de confiança de Zucker (1998), em que foi questionada a existência de familiares (confiança baseada em características); as principais relações comerciais mantidas entre os atores (relações comerciais), e as relações não comerciais, formadas pelas amizades e atuação conjunta anterior, quer como empregados, quer em sociedades anteriores (confiança baseada em processos); e a identificação daqueles atores com melhor reputação e o pertencimento conjunto em associações (confiança baseada em instituições).

Os dados relacionais foram inicialmente tabulados com software Microsoft Excel, para serem posteriormente transferidos para os softwares UCINET 6.171 e PAJEK 1.10 , onde foi realizada a análise de redes sociais do grupamento de empresas. Foram analisados os aspectos relacionais de confiança baseada em características, formadas pelas relações familiares entre os empresários do setor, e as relações de compadrio dos mesmos; de confiança baseada em processos, baseada em relações comerciais e não comerciais, que por sua vez são compostas pelas relações de amizade e pela possibilidade de prévio trabalho conjunto em atividades anteriores; e de confiança baseada em instituições, baseada na reputação dos empresários e pelas associações e agremiações a que os mesmos pertencem. Basicamente a ARS 
operacionaliza o estudo das relações a partir do estudo de sociogramas matriciais, da existência ou não de relação, mediante a inclusão de 0 para inexistência de relação entre os atores e 1 para relação existente. Daí obtém-se matrizes simétricas binárias, do tipo $A^{*} A^{\prime}$ já que todos os atores relacionados são também citados e dispostos ordenadamente, e somente existem duas possibilidades de vínculo, existência ou não de relação (Molina, 2001).

Para se analisar individualmente cada ator, foram utilizadas diferentes medidas de centralidade, nomeadamente, o grau de centralidade, o grau de intermediação e a centralidade geodésica. O grau de centralidade (Degree) é utilizado em redes simétricas que se manifesta pelas relações diretas de cada ator (RODRIGUES E MÉRIDA, 2006). Ela é medida pelo número de laços diretos que um ator possui com outros demais em uma rede (Wasserman e Faust, 1994). Para Wasserman e Faust (1994), na centralidade de intermediação (Betwenness) a interação entre atores não adjacentes pode depender de outros, que podem potencialmente ter algum controle sobre estas interações. Indica ainda, para cada ator em que medida está em uma posição intermediária nas comunicações geodésicas, ou seja, as distâncias mais curtas, em relação aos demais atores. A centralidade geodésica (Eigenvector ou Bonacich Centrality) permite identificar os atores mais centrais em termos de estrutura central da rede. Observam-se menos as posições individuais de cada ator, ou seja, a centralidade local (WASSERMAN E FAUST, 1994). Os resultados obtidos de cada um destas medidas de centralidade foram agrupados em um único índice, baseado em Cadima (2009), com variação de 0 a 1, a partir da seguinte fórmula:

$$
\text { Indice }=\frac{(d / D)+(b / B)+(g / G)}{3}
$$

Onde: $d=$ grau de centralidade da empresa;

$D=$ maior grau de centralidade entre as empresas

$b=$ grau de intermediação da empresa

$\mathrm{B}=$ maior grau de intermediação entre as empresas

$\mathrm{g}=$ centralidade geodésica da empresa

$\mathrm{G}=$ maior centralidade geodésica entre as empresas

A principal razão da utilização deste índice unificado foi impedir que, por suas características conceituais, um determinado tipo de centralidade acabasse por criar vieses no modelo proposto. Assim criou-se um indicador para cada dimensão relacional avaliada no estudo, de forma que foi obtido um índice para características e para amizade, por exemplo. 
Para a determinação destas centralidades foi utilizado o software Ucinet 6,171. A seguir, com o uso do software SPSS 19.0 analisou-se o impacto de cada uma destas dimensões sobre aquela que compunha e sobre o índice gerado. O mesmo software foi empregado na determinação da relação entre as diferentes dimensões relacionais, pela análise de regressão e correlação entre as variáveis. Para a determinação da coesão social do grupo foi utilizado o software PAJEK 1.10 para a construção de sociogramas ou mapas relacionais de cada uma das dimensões analisadas.

\section{Análise dos dados}

Ao todo foram observadas 953 relações em todas as dimensões pesquisadas, de um total de 13250 relações possíveis a partir dos 53 respondentes, com média de 17,98 relações por empresa, envolvendo 250 distintos atores. As medidas de centralidade dos atores é apresentada no Quadro 1.

\begin{tabular}{|l|r|r|r|}
\hline Empresa & \multicolumn{1}{|c|}{ Grau } & Intermediação & Geodésica \\
\hline Ac1 & 11,647 & 3,677 & 20,508 \\
\hline Ac10 & 13,253 & 6,594 & 21,017 \\
\hline Ac11 & 7,229 & 1,591 & 12,643 \\
\hline Ac12 & 7,631 & 2,57 & 10,232 \\
\hline Ac13 & 8,434 & 2,315 & 14,005 \\
\hline Ac14 & 2,811 & 1,022 & 2,637 \\
\hline Ac15 & 10,442 & 7,2 & 15,012 \\
\hline Ac16 & 9,237 & 2,932 & 15,762 \\
\hline Ac17 & 13,655 & 3,959 & 28,752 \\
\hline Ac18 & 14,056 & 4,69 & 25,112 \\
\hline Ac19 & 16,867 & 9,307 & 23,888 \\
\hline Ac2 & 9,639 & 4 & 14,61 \\
\hline Ac20 & 9,237 & 2,922 & 15,998 \\
\hline Ac21 & 6,827 & 2,681 & 11,011 \\
\hline Ac22 & 7,631 & 1,535 & 13,923 \\
\hline Ac3 & 23,293 & 16,141 & 39,813 \\
\hline Ac4 & 16,064 & 6,192 & 33,649 \\
\hline Ac5 & 9,237 & 3,993 & 10,522 \\
\hline Ac6 & 10,843 & 4,552 & 13,405 \\
\hline Ac7 & 8,835 & 1,901 & 10,712 \\
\hline Ac8 & 12,048 & 4,197 & 21,889 \\
\hline Ac9 & 12,851 & 4,257 & 21,921 \\
\hline C1 & 11,647 & 4,599 & 20,604 \\
\hline C2 & 18,072 & 7,066 & 36,339 \\
\hline C3 & 3,426 & 1,077 & 11,711 \\
\hline Com1 & 7,631 & 1,588 & 14,79 \\
\hline Com2 & 7,631 & 1,299 & 15,785 \\
\hline
\end{tabular}

\begin{tabular}{|l|r|r|r|}
\hline Empresa & Grau & Intermediação & Geodésica \\
\hline Com3 & 7,631 & 2,169 & 13,74 \\
\hline Com4 & 6,827 & 1,631 & 9,684 \\
\hline Com5 & 3,614 & 0,475 & 3,26 \\
\hline Com6 & 5,221 & 0,861 & 8,087 \\
\hline Com7 & 5,622 & 0,967 & 4,961 \\
\hline Com8 & 3,614 & 1,69 & 6,442 \\
\hline Pex1 & 7,229 & 4,722 & 12,435 \\
\hline Pex2 & 5,622 & 1,25 & 8,824 \\
\hline PQF1 & 6,024 & 1,353 & 12,245 \\
\hline PQF2 & 7,631 & 0,906 & 16,51 \\
\hline PQR1 & 8,434 & 14,493 & 19,42 \\
\hline PQR2 & 8,835 & 2,717 & 19,275 \\
\hline PQR2 & 6,827 & 0,899 & 14,982 \\
\hline PQR3 & 8,434 & 3,005 & 13,779 \\
\hline PQR4 & 11,647 & 6,396 & 17,903 \\
\hline PQR5 & 7,631 & 2,641 & 11,235 \\
\hline PQR6 & 9,237 & 2,031 & 17,644 \\
\hline Serv1 & 10,04 & 3,06 & 18,512 \\
\hline Serv2 & 10,442 & 5,87 & 14,102 \\
\hline Serv3 & 10,843 & 2,97 & 17,918 \\
\hline Serv4 & 7,229 & 1,632 & 11,098 \\
\hline Serv5 & 8,835 & 2,367 & 15,708 \\
\hline Serv6 & 8,434 & 2,522 & 15,035 \\
\hline Serv7 & 6,024 & 2,388 & 11,95 \\
\hline Serv8 & 7,229 & 1,398 & 13,361 \\
\hline Serv9 & 7,631 & 1,491 & 20,654 \\
\hline & & & \\
\hline
\end{tabular}

Quadro1: : Medidas de centralidade da rede social dos curtumes de Estância Velha 
O grau de centralidade apresenta apenas Ac3 com valores acima de $20(23,293)$, seguido de C2, Ac 19 e Ac4 acima de 15 (respectivamente 18,072, 16,867 e $16,064)$, seguidas de um conjunto de 13 empresas com valores acima de 10 e um bloco de 33 empresas com valores entre 10 e 5 . Por último aparecem três empresas com valores inferiores a 5 , Com5 $(3,614)$, Com $8(3,614)$ e Ac14 $(2,811)$

Em termos de intermediação, somente Ac3 possui valor acima de $10(13,414)$, seguido de um grupo de 7 empresas com valor acima de 5, 40 empresas com valores entre 5 e 1 e cinco empresas com valores inferiores a 1 . A centralidade geodésica mostra Ac3 também com maior resultado $(39,813)$, seguido de C2 e Ac4 com valores acima de 30 (respectivamente 36,339 e 33,649), seguidos de um grupo de 9 empresas com valores entre 20 e 30, 34 empresas com valores entre 10 e 20 e sete empresas com valores inferiores a 10.

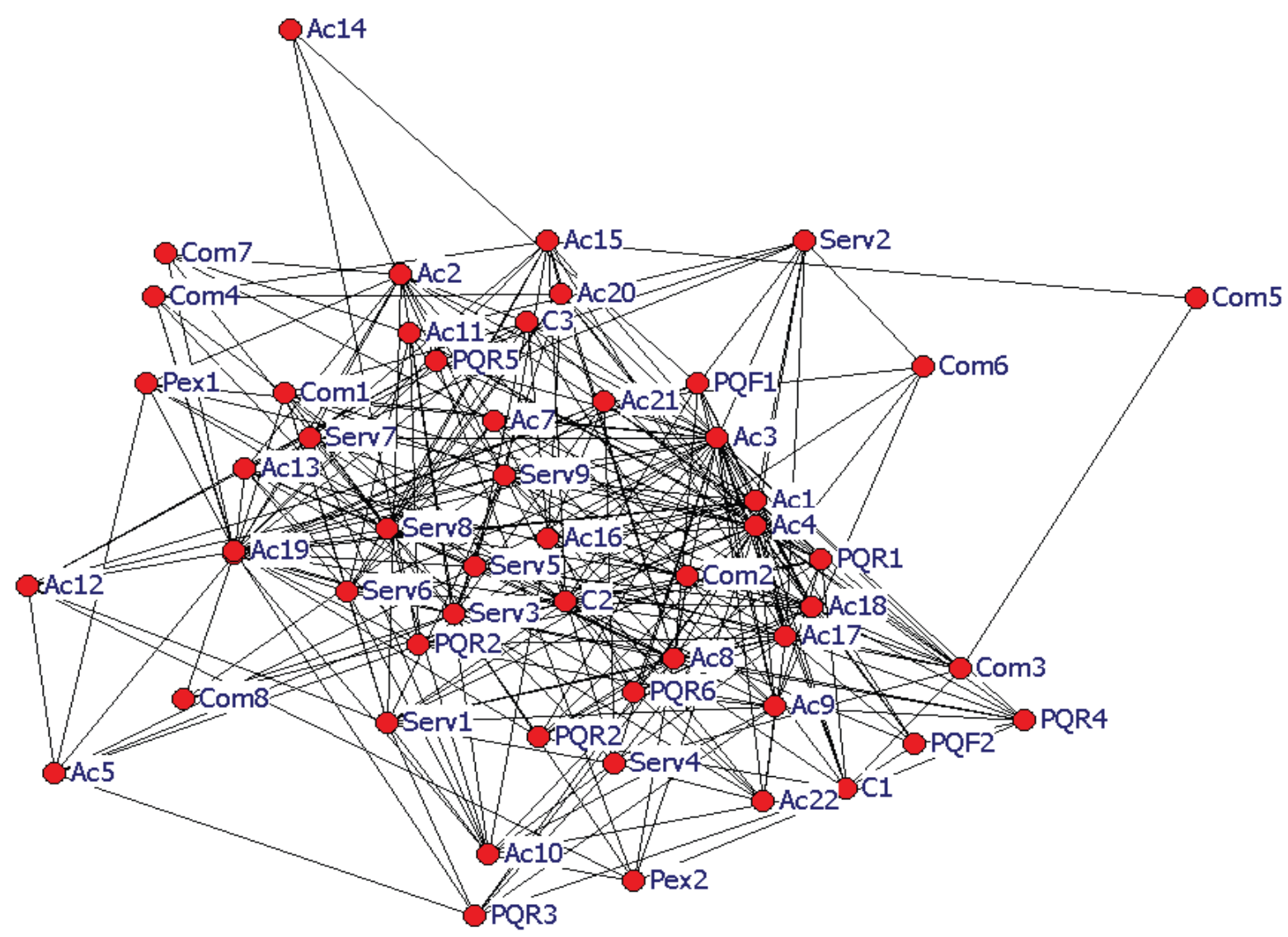

FIGURA 1: mapa relacional das organizações estudadas, considerando as relações extra-rede.

Ao se considerar todas as forças relacionais oriundas tanto das empresas pesquisadas, como daquelas externas à rede, obtemos a figura 1. Nela podemos observar em particular a posição central ocupada por C2 e o afastamento de Ac14 e 
Com 5. Observa-se ainda um grande deslocamento de Ac3 e outros atores centrais. Desta comparação pode-se pressupor que efetivamente o impacto das relações extra-rede é altamente significativo, ao se analisar a estrutura social de uma rede de empresas.

\section{Relação entre os índices relacionais}

A partir de uma série de regressões múltiplas analisaram-se os elementos componentes do índice de relacionamento geral, considerando-o como variável dependente. Inicialmente, consideraram-se apenas os índices relacionais diretamente ligados a ele, nomeadamente, o índice relacional baseado em características, em processos e em instituições. Foi identificado um alto nível de significância na correlação entre estes indicadores e o índice relacional geral. A partir desta informação, partiu-se para uma análise de regressão múltipla onde se identificou que estas três variáveis respondem por 93,8\% do índice relacional geral. Pelo coeficiente de Beta padronizado que tanto o índice relacional baseado em instituições, quanto o baseado em processos são significativos, sendo que seus impactos são respectivamente de $51,8 \%$ e $52,8 \%$. As relações baseadas em características foram àquelas formadas pelas relações familiares. Tais relações tiveram muito baixo impacto sobre o índice relacional. Tal fato pode ser explicado pelo pequeno número de nascidos no município.

Na reputação, as associações acabam por ocupar uma posição bastante central no que tange ao estabelecimento de relações entre os membros da rede, já que uma parte significativa das empresas não participa de nenhuma forma de associação, aquelas que dela participam parecem se beneficiar de forma bastante importante deste fato. É justamente a reputação, o elemento que mais impacta no índice geral de confiança, sendo que o mesmo apresenta clara relação com a amizade e com as relações comerciais, todavia, destacando-se a amizade como de mais alta correlação.

Deste conjunto de relações obteve-se um mapa das relações formadas pelos empresários do setor, considerando-se todas as relações citadas. Ao todo foram observadas 953 relações, de um total de 13250 relações possíveis a partir dos 53 respondentes, com média de 17,98 relações por empresa, envolvendo 250 distintos atores. Observa-se que mesmo a relação institucional não considerando as relações externas ao grupo pesquisado, 11 empresas e instituições apresentaram alto grau de centralidade no estudo desenvolvido, nomeadamente 3 associações e agremiações, 3 curtumes completos, 3 empresas de produtos químicos e duas acabadoras de couros. Curiosamente não se observou nenhum fabricante de 
calçados nesta posição. Isto pode se dever tanto pela concentração de fornecimento das fábricas de calçados por motivos logísticos, quanto pelo receio dos respondentes em expor a relação de seus clientes calçadistas.

Também puderam ser observadas diferenças ao se analisar as características das empresas e dos atores envolvidos nas relações. Empresas mais antigas e de maior porte, bem como as exportadoras e aquelas geridas por pessoas com maior formação educacional ou freqüentadoras da escola técnica existente na cidade demonstraram maior capacidade de aproveitamento de suas relações sociais.

A seguir analisou-se o índice relacional baseado em processo como variável dependente. Identificaram-se também significativos valores de correlação entre este índice e as relações comerciais e não comerciais, com poder explicativo de $90,7 \%$. Os coeficientes de Beta padronizado tanto para o índice relacional baseado em relações comerciais, quanto o baseado em relações não comerciais foram significativos, sendo que seus impactos são respectivamente de 49,6\% e 65,0\%. Com impacto superior a $50 \%$ sobre o índice geral, este conjunto de relações apresentou-se bastante significativo, observou-se ainda que uma série de empresas de outras localidades teve grande importância no conjunto destas relações. Esta centralidade deslocada para empresas de fora da rede analisada se deveu tanto a relações comerciais, como não comerciais. O fato de a cidade estar integrada em um aglomerado maior, o Vale dos Sinos, e com as demais regiões calçadistas pode justificar esta maior importância das relações extra-rede.

As relações comerciais analisadas envolveram o conjunto de relações das empresas com seus clientes e fornecedores. Observou-se que 13 empresas externas à rede analisada acabaram por ocupar uma posição bastante central, o que pode ser explicado através do fato destas empresas serem, ou grandes clientes, ou grandes fornecedores (em especial, multinacionais da indústria química), o que Ihes dá maior importância na rede. As empresas prestadoras de serviços, por terem um conjunto mais variado de relações e atuarem como clientes e fornecedores ao mesmo tempo de empresas localizadas tanto no interior como fora da rede, acabam por ter uma maior centralidade. Destaca-se o caso específico de Ac3, empresa de maior centralidade da rede, e que foi a única empresa que mencionou ter uma estratégia relacional sistematizada com seus clientes e fornecedores.

Para a compreensão da dimensão não comercial, adotou-se a mesma técnica, considerando-a agora, como variável dependente das relações de amizade e dos locais anteriores de trabalho. Novamente foi observada correlação entre os índices, com poder explicativo da variável dependente de $86,3 \% .13,6 \%$ do índice de 
relacionamento não comercial foi explicado a partir dos locais anteriores de trabalho dos respondentes, enquanto as relações de amizade foram responsáveis por $89,5 \%$ das mesmas.

As relações de amizade se tornam importantes principalmente para empresas focadas na prestação de serviços. Observa-se uma estrutura relacional de amizade menos densa e diversificada que as relações comerciais. O número de contatos estabelecidos é menor e envolvendo um menor número de empresas externas. Observam-se ainda, relativamente poucas empresas externas relacionalmente no interior do grupo de empresas mais centrais. Quanto ao local de atuação anterior, foram identificados claramente subgrupos formados pela atuação em empresas anteriores, o que permite indicar que a atuação em empresas anteriores, mesmo que não ocorrida em um período de tempo concomitante, pode ter força relacional significativa.

O índice de relações baseadas em instituições também foi analisado e da mesma forma apresentou alto nível de significância entre este e suas variáveis preditoras, tanto associações, quanto reputação. $98,2 \%$ da variação do índice relacional baseado em instituições são explicados pelas associações e pela reputação, sendo aquela tem poder explicativo de $22,5 \%$ enquanto esta, $87,5 \%$. Buscando ainda a compreensão do impacto das dimensões relacionais que não atuam diretamente sobre o índice relacional geral.

Considerando este como dependente, identifico-se alta significância para todos os índices a exceção do índice de trabalho anterior cuja significância apresentou o valor de 0,134. Identificou-se que estes índices têm capacidade explicativa de $91,9 \%$ do Índice relacional geral e na análise dos coeficientes Beta padronizados identificaram a reputação como elemento com maior poder preditivo com 50,2\%, seguido da Amizade com 30,9\%, relações comerciais com 24,6\%, Associações com $12,2 \%$ e trabalho anterior com $6,8 \%$.

Quanto a reputação, destaca-se a atuação de Ac3, que como em outras dimensões também apresentou posição central. Identificou-se nesta forma de relação uma alta influencia das relações com as associações.

Como a reputação apresentou índices muito altos de poder explicativo sobre o índice relacional geral, procurou-se identificar quais outros índices poderiam ter impacto significativo sobre ela. Foram identificados apenas dois índices com valores significativos, nomeadamente relações comerciais e amizade. A análise de regressão múltipla considerando a reputação como variável dependente destes dois 
índices apresenta poder explicativo de $43,0 \%$, sendo que a amizade é responsável por $46,6 \%$ e as relações comerciais por $30,3 \%$.

Como base todas estas informações, de forma a resumir e permitir a visualização deste conjunto de correlações foi criada a figura 2. Nela é possível identificar-se que as relações baseadas em processos e àquelas baseadas em instituições tem pesos equivalentes, enquanto a baseada em características teve baixo impacto neste grupo.

Que as relações não comerciais têm maior impacto que as relações comercias naquelas baseadas em processos, sendo que o principal componente nas relações não comerciais são as relações de amizade e não aquelas oriundas de trabalhos conjuntos anteriores. Já nas relações baseadas em instituições, é a reputação o elemento determinante, ocupando a participação em associações uma função secundária.

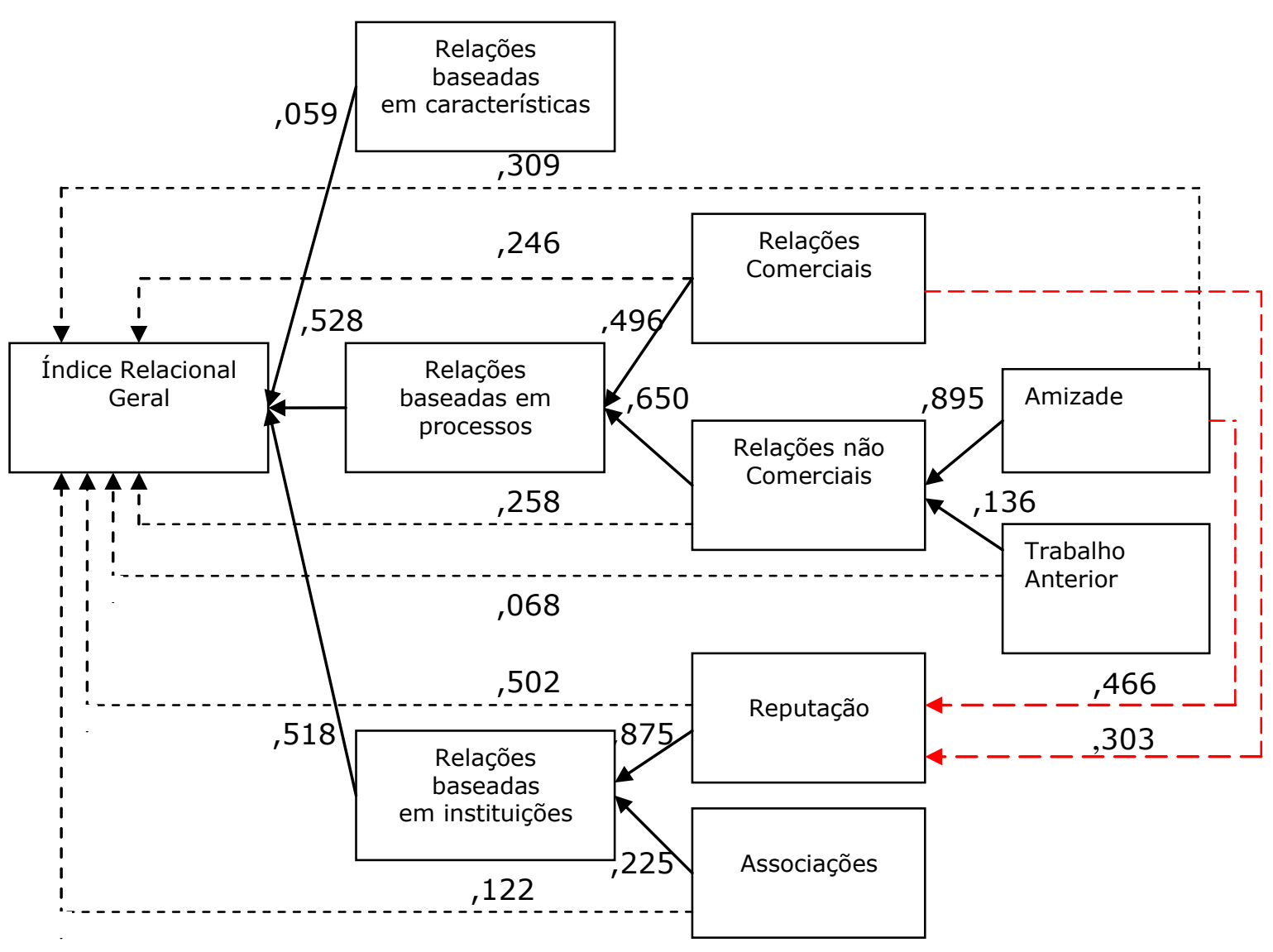

Figura 2: Representação da relação entre os diferentes índices. 
A partir dos dados oriundos das relações sociais as empresas foram analisadas em função de suas diversas características particulares, observando-se de que forma estes dois índices variaram em função de suas diferenças. Os resultados são apresentados na tabela 2 .

Comparando-se o Índice relacional em relação ao tamanho das empresas, observase que este aumenta com o tamanho da empresa. $O$ índice relacional passa de 0,2600 para 0,4732, daí somente poder-se supor que o aumento do tamanho implique em uma melhora dos índices considerados, podendo-se sugerir que as relações sociais sejam mais bem aproveitadas pelas empresas de maior porte, por possuírem uma melhor estrutura organizacional no sentido deste aproveitamento.

Ao se comparar às empresas por antiguidade, e desconsiderando-se os grupos formados por empresas fundadas anteriormente a 1980, devido ao baixo número de casos, observa-se um aumento do índice relacional no tempo. Tal resultado corrobora com a idéia de que as relações são cultivadas com o tempo, de forma que existe uma relação direta entre o tempo de existência das empresas e suas relações sociais.

\begin{tabular}{|l|c|r|}
\hline Fundação & Média & N \\
\hline $1981-1990$ &, $3759 *$ & 12 \\
\hline $1991-2000$ &, $3190 *$ & 13 \\
\hline $2001-2007$ &, $2508 *$ & 21 \\
\hline
\end{tabular}

\begin{tabular}{|l|r|r|}
\hline Tamanho & Média & $\mathrm{N}$ \\
\hline Micro &, $2600^{*}$ & 28 \\
\hline Pequena &, $3333^{*}$ & 17 \\
\hline Média &, $4732 *$ & 5 \\
\hline
\end{tabular}

\begin{tabular}{|l|c|r|}
\hline Escolaridade & Mean & N \\
\hline Fundam. Médio &, $2963^{*}$ & 29 \\
\hline Superior &, $3358^{*}$ & 13 \\
\hline
\end{tabular}

\begin{tabular}{|l|l|r|}
\hline Escola Técnica & Média & \multicolumn{1}{|c|}{$\mathrm{N}$} \\
\hline Egressos &, $3935 * *$ & 14 \\
\hline Não alunos &, $2723 * *$ & 36 \\
\hline
\end{tabular}

\begin{tabular}{|l|c|r|}
\hline Exporta & Mean & N \\
\hline Sim &, $4376 * *$ & 7 \\
\hline Não &, $2849 * *$ & 43 \\
\hline
\end{tabular}

Teste $t$

$$
\begin{aligned}
& *<0,05 \\
& * *<0,01
\end{aligned}
$$

Quadro 2: Características relacionais dos diferentes grupos de respondentes.

Analisando-se o nível de escolaridade dos respondentes, observa-se que aqueles com formação superior apresentam índice relacional mais alto. Pessoas com maior nível de formação podem ser capazes de melhor se apropriar das vantagens de seu círculo social. Considerando os egressos da Escola de Curtimento Senai RS, observa-se estes tem índice relacional mais alto que os não egressos desta escola. O fato de estes empresários terem uma formação comum, permite atuar como facilitador das relações, já que muitos podem se conhecer desde os tempos de 
estudo, e por outro, a formação comum pode permitir aos demais a antevisão de suas ações. Na comparação entre as médias das empresas exportadoras e não exportadoras, observa-se que as que atuam nos mercados internacionais têm maior índice relacional que aquelas que não exportam. O índice relacional daquelas é de 0,4376, enquanto das que não exportam é de 0,2849. Tal fenômeno pode se dever ao fato que as empresas mais bem estruturadas, e que assim podem exportar, também são mais capazes de absorver as vantagens relacionais.

\section{Considerações Finais}

Este estudo analisou a influencia das relações sociais dos executivos no desempenho individual em aglomerações de empresas. Para tal, foram analisadas as relações das empresas do setor couro da cidade de Estância Velha.

Espera-se que este trabalho ajude a demonstrar a necessidade de se desenvolver cada vez mais o uso de metodologias eficazes em medir a confiança nos relacionamentos socioeconômicos, bem como que se aperceba da possibilidade de analises relacionais quantitativas nestes contextos.

O tema, porém, pela dubiedade característica, demanda muitos e maiores aprofundamentos em futuros estudos, tanto na definição das formas de relação e confiança existentes, quanto no modo de maximização das mesmas e no exame dos efeitos dos tipos de relação e confiança na eficiência das empresas.

O reconhecimento que os efeitos da confiança variam dependendo do contexto organizacional é uma etapa importante em aumentar a compreensão da confiança nas organizações. Acredita-se que somente após o entendimento de um modelo conceitual da confiança nas relações interorganizacionais possa ser possível influenciar eficazmente o tipo e o nível da confiança que os membros apresentam.

Apesar da grande importância mencionada anteriormente, a confiança nas relações empresariais ainda apresenta-se muito vaga e espera-se que, com este trabalho uma maior transparência no entendimento do tema tenha sido alcançada, de forma a conduzir a uma melhor compreensão do fator humano dos atores econômicos.

Talvez a principal implicação gerencial seja a de permitir ao empresário identificar sua posição relacional no grupo de empresas e permitir a comparação de sua posição com os demais, de forma a lhe permitir traçar estratégias de desenvolvimento de relações no sentido de melhor se posicionar em termos relacionais. Criar relações representa custo e sabendo-se inicialmente da necessidade e do impacto deste na geração de eficiência organizacional, o empresário pode se sentir mais disposto a fazê-lo. No grupo estudado, estas 
estratégias deveriam estar mais concentradas na ampliação da reputação, que por sua vez, deveria estar vinculada à diversificação das relações de amizade.

As principais implicações para uma análise setorial estão ligadas à identificação dos atores mais centrais de qualquer rede social pode ser um grande facilitador quando se deseja implementar qualquer política de cooperação, porque em caso destes adotarem a idéia da cooperação, a adesão dos demais se tornará teoricamente muito mais fácil. Mas não somente estes, como também àqueles que ocupam alta centralidade nos subgrupos podem ser de significativa importância em processos em que se necessite a concordância de todos.

Várias são as limitações deste trabalho, em especial identificou-se na falta de dados secundários que confirmassem as relações propostas, uma de suas maiores limitações, assim ficou-se dependente das assertivas dos respondentes. Também na descrição de suas dificuldades operacionais, essa dependência se manteve, se fazendo necessário em estudos futuros que se procure identificar formas de confirmação das informações recebidas.

Importante também é a compreensão de que as relações estão em permanente mutação, como o período de coleta de dados foi relativamente longo, de três meses, fatores externos podem ter influenciado nas respostas. Outra limitação importante é que cada pessoa tem seu próprio conjunto de relações. Considerou-se somente as relações formadas pelos sócios e executivos das empresas, porém os demais funcionários podem ter um círculo de relações que sejam significativas para a organização. Uma recomendação para estudos futuros é abrir o leque de respondentes para mais pessoas responsáveis pelos contatos externos da organização.

Além disso, analisou-se um arranjo produtivo com alto grau de interação com empresas externas ao grupo pesquisado, cujo impacto nas relações deste grupo foram significativamente altos. Outra recomendação para estudos futuros é a análise de grupos mais fechados de empresas, como forma de obtenção de um quadro mais bem definido das relações e que permita inclusive identificar o impacto das relações externas de forma mais clara, se o número destas for menor. A replicação deste modelo em outros arranjos produtivos e em outras formas de organização em rede também se faz necessária, como forma de validação deste tipo de análise e de seus construtos. Uma dificuldade natural é a necessidade de este tipo de estudo ter base censitária, já que amostras não têm poder generalizador para a população, o que o torna especialmente mais oneroso e desgastante. 


\section{Bibliografia}

Barney, J.B.; Hansen, M.H. (1994) Trustworthiness as a source of competitive advantage. In: Strategic Management Journal. v. 15, Special Issue, p. 175-190.

Becattini, G. (1999). Os distritos industriais na Itália. In: URANI, A.; COCCO, G.;Galvão, A. P. (org.) Empresários e empregos nos novos territórios produtivos: 0 caso da terceira Itália; - Rio de Janeiro: DP\&A.

Becattini, G. (2002). El Distrito Industrial Marshalliano a la Teoría del Distrito Contemporánea. Una Breve Reconstrucción Critica. in Investigaciones Regionales, otoño, no 01, Asociación Española de Ciencias Regionales. Alcalá de Henares, p 932.

Bonnacich P. (1972). Techniques for analyzing overlapping memberships. Sociological Methodology 176-185 Jossey-Bass.

Bourdieu, P. (1998). O Capital Social: notas provisórias. In: Nogueira, M. A.; Catani, A.(org). Escritos de Educação. Petrópolis, Vozes.

Borgatti, S.P.;. Everett M.G. (1997). Network analysis of 2-mode data. Social Networks 19(3): 243-270.

Britto, J. (2002). Cooperação Industrial e Redes de Empresas. In: KUPFER, D; Hasenkever L. (org.) Economia Industrial, Rio de Janeiro, Elsevier.

Cadima R. A. C. D. (2009) Monitorização de redes sociais na gestão do conhecimento em comunidades de $I+D+i$ Tesis de doctorado Programa de Doctorado en Ingeniería Multimedia. Universidad Politécnica de Cataluña.

Coleman, J. S. (1988). Social Capital in the Creation of Human Capital. In: Americam Journal of Sociology, vol. 94 Pg 95-120.

de Wever, S.; Martens, R.; Vandenbempt K. (2005). The impact of trust on strategic resource acquisition through interorganizational networks: Towards a conceptual model. Human Relations, 58(12), 1523-1543.

Emirbayer, M.; Goodwin, J. (1994). Network analysis, culture and the problem of agency. American Journal of Sociology, v.99, n.6, p. 1411-54, May.

Forni, P., Siles, M., Barreiro, L. (2004). "¿Qué es el Capital Social y cómo Analizarlo en contextos de Exclusión?", en: www.jsri.msu.edu.

Fukuyama, F. (1996). Confiança: as virtudes sociais e a criação da prosperidade. Rio de Janeiro: Rocco. 
Granovetter, M. (1973). The strength of weak ties. American Journal of Sociology, Chicago, v. 78, n. 6, p. 1360-1380, May.

Gray D. (2006). Networks and social capital in Europe - the sociological perspective: Networks, Trust and Social Capital: Theoretical and Empirical Investigations from Europe. In: International Journal of Entrepreneurship and Innovation, $7(2), 130-131$.

Hanneman, R. A. (2001). Introducción a los métodos del análisis de redes sociales. Disponível em: http://revista-redes.rediris.es/webredes/. Acesso em: 03 novembro 2006.

Kramer, R. (1999). Trust and Distrust in Organizations: Emerging perspectives, enduring questions. Annual Review of Psychology, v. 50, p. 569-598.

Kwong P. Y. (2002). An action-based perspective of firm heterogeneity: Source of competitive advantage Ph.D. Chinese University of Hong Kong (People's Republic of China), 191 pages; AAT3052099.

Levin, D. Z.; Cross, R. (2004). The Strength of Weak Ties You Can Trust: The Mediating Role of Trust in Effective Knowledge Transfer. In: Management Science, $50(11), 1477-1490$.

Lewis JD.; Weigert A. (1985). Trust as a social reality. In: Social Forces v.63, p.967-985.

Marshall, A. (1984). Princípios de economia. São Paulo: Nova Cultural.

Molina J. L. (2001). El Análisis de Redes Sociales. Una Introducción. Barcelona: Ediciones Bellaterra/SGU.

Morrow, Jr.; J.L., Hansen,H.H.; Batista, J.(1999). Measurement Issues in Trust Research: Are We Measuring What We Think We're Measuring? In: IAMA Agribusiness Forum, Florence: Italy.

Nahapiet, J.; Ghoshal, S. (1998). Social capital, intellectual capital, and the organizational advantage. Academy of Management Review, 23(2), 242-66.

Oh, H.; Labianca, G.; Chung, M. H. (2006). A Multilevel Model of Group Social Capital. In: Academy of Management Review, Vol. 31(3) 569-582.

Patulny R. V.; Svendsen G. L. H. (2007). Exploring the social capital grid: bonding, bridging, qualitative, quantitative. In: The International Journal of Sociology and Social Policy, 27(1/2), 32-51. 
Porter M. E. (1999). Competição on Competition: Estratégias Competitivas Essenciais. Rio de Janeiro: Campus.

Putnam, R. (1996). Comunidade e democracia: a experiência da Itália moderna. Rio de Janeiro: FGV.

Rodriguez J.; Mérida F. (2006). UCINET 6.0 Guía Práctica de Redes Sociales. Universitat de Barcelona.

Rousseau, D.; Sitkin, S.; Burt, R.; Camerer, C. (1998). Not so different after all: a cross discipline view of trust. Academy of Management Review. v. 23, 3, p. 393404.

Scott, A. (1998). The geographic foundations of industrial performance. In: A. Chandler, Jr., Hagstrom, P. and Solvell, O. (1998), (eds.), The Dynamic Firm - The Role of Technology, Organization and Regions. Oxford: Oxford University Press.

Singh, J.; Sirdeshmukh, D. (2000). Agency and Trust Mechanisms in Relational Exchanges. Journal of the Academy of Marketing Science, v. 28, p. 150-167, winter.

Scott, J. (2000). Social network analysis: a handbook. 2 ed. London: Thousands Oaks, Calif.: Sage Publications. 208 p.

Sobel, J. (2002). Can we trust social capital?, Journal of Economic Literature, Vol. 40, pp. $139-54$.

Uzzi B. (1997). Social Structure and Competition in Interfirm Networks: The Paradox of Embeddedness. In: Administrative Science Quarterly, Vol. 42.

Vainio A. M. (2005). Exchange and combination of knowledge-based resources in network relationships: A study of software firms in Finland. In: Journal of Marketing, 39 (9/10), 1078-1095,1222.

Wasserman, S.; Faust, K (1994). Social Network Analysis: Methods and Applications. Cambridge: Cambridge University Press.

Zucker, L. G. (1986) Production of Trust: Institutional Sources of Economic Structure, 1840-1920 Research in Organizational Behavior, Vol. 8, p. 53-111. 